Artigos Originais

\title{
Uma visão da gestão da oferta do Turismo de Natureza no Parque Nacional do Caparaó (ES/MG)
}

\author{
Nature tourism offer management at Parque Nacional do Caparaó (Brazil) - an overview \\ Una visión de la gestión de la oferta del turismo de naturaleza en el Parque Nacional do Caparaó (Brasil) \\ Victor Silveira Massini \\ Universidade Federal do Espirito Santo, Brasil \\ DOI: https://doi.org/10.18472/cvt.21n3.2021.1838 \\ massini.ufop@gmail.com \\ Redalyc: https://www.redalyc.org/articulo.oa? \\ id $=115469516004$
}

Cláudia Câmara do Vale

Universidade Federal do Espirito Santo, Brasil

camaravale@gmail.com

Ricardo Eustáquio Fonseca Filho

Universidade Federal de Ouro Preto, Brasil

ricardo.fonseca@ufop.edu.br

Recepción: 15 Julio 2020

Aprobación: 08 Octubre 2021

\section{Resumo:}

O turismo de natureza é um dos tipos de turismo mais buscados atualmente, em especial para contemplação e lazer. O Parque Nacional do Caparaó (PNC), localizado entre os estados de Espírito Santo e Minas Gerais, é um exemplo deste tipo de atrativo. O objetivo do trabalho foi identificar a gestão da oferta do turismo de natureza e as relaçóes com a Unidade de Conservação. A metodologia consistiu em revisão de literatura e elaboração de instrumentos de coletas de dados (questionário estruturado qualitativo), para entrevistas in loco de 11 atores sociais (um gestor público e 10 empreendedores privados), aplicadas em 2017. Como resultados, a pesquisa demonstrou que os atrativos naturais e culturais são elementos enriquecedores na oferta turística, enquanto a falta de planejamento e o uso indiscriminado configuram-se como ameaças à aspectos qualitativos dos destinos. Concluiu-se que um melhor planejamento turístico da região é necessário, com revisão do plano de manejo do PNC e maior integração entre setor público e privado na gestão do turismo de natureza.

Palavras-chave: Planejamento Turístico, Oferta Turística, Segmentação Turística, Patrimônio Natural, Áreas Naturais Protegidas.

\section{ABSTRACT:}

Nature tourism is one of the most sought-after types of tourism today, especially for contemplation and leisure. The Parque Nacional do Caparaó (PNC), located between the states of Espírito Santo and Minas Gerais - Brazil, is an example of this type of attraction. The aim of this work was to identify the management of offer of nature tourism and how it relates with the Natural Protected Area. The methodology has considered a literature review and elaboration of data collection instruments (qualitative structured questionnaire) for on-the-spot interviews with a sample of 11 stakeholders (one public manager and 10 private entrepreneurs), applied in 2017. As results, the research demonstrated that natural and cultural attractions are enriching elements in the tourist offer, while the lack of planning and the indiscriminate use are configured as threats to qualitative aspects of destinations. It was concluded that there is a need for better tourism planning in the region, with the revision of the PNC management plan and the increased integration of public and private sectors in the management of nature tourism.

KEYWORDs: Tourism Planning, Tourist Offer, Tourism Segmentation, Natural Heritage, Natural Protected Area.

\section{ReSUMEN:}

El turismo de naturaleza es uno de los tipos de turismo más buscados en la actualidad, principalmente para contemplación y ocio. El Parque Nacional do Caparaó (PNC), ubicado entre los estados de Espírito Santo y Minas Gerais - Brasil, es un ejemplo de este tipo de atracción. El objetivo de este trabajo fue identificar la gestión de la oferta turística de naturaleza y las relaciones con el Área Protegida. La metodología consistió la revisión bibliográfica y la elaboración de instrumentos de recolección de datos (cuestionario 
estructurado cualitativo) para entrevistas in situ, con una muestra de 11 actores sociales (un directivo público y 10 emprendedores privados), aplicada en 2017. Como resultados, la investigación demostró que los atractivos naturales y culturales son elementos enriquecedores de la oferta turística, mientras que la falta de planificación y el uso indiscriminado se configuran como amenazas a los aspectos cualitativos de los destinos. Se concluyó que existe la necesidad de una mejor planificación turística en la región, con la revisión del plan de manejo del PNC y una mayor integración entre los sectores público y privado en la gestión del turismo de naturaleza.

Palabras clave: Planificación Turística, Oferta Turística, Segmentación Turística, Patrimonio Natural, Áreas Naturales Protegidas.

\section{INTRODUÇÃo}

Áreas naturais protegidas, como são as unidades de conservação (UCs), representam uma tentativa social de resguardar e garantir a manutenção dos recursos naturais e da biodiversidade, para tratá-los de forma mais adequada e segura (Ferreira \& Oliveira, 2019). A criação de uma UC visa ainda a proteção de aspectos de caráter paisagístico que sejam de incomparável expressividade (MMA, 2004).

No entanto, nem sempre esta relação entre o uso e a conservação dos recursos é harmônica. Há diferentes interesses que tornam a gestão destas áreas um desafio (MMA, 2004). Para o Instituto Chico Mendes de Conservação da Biodiversidade (ICMBio, 2018b, p.4), para além da conservação, "a estruturação da unidade de conservação para as atividades de uso público cria novas oportunidades de negócios". Por sua vez, os usos públicos - dentre eles o turismo - podem também gerar impactos socioambientais negativos (Takahashi, 2004).

Uma das categorias de UCs que destaca a conciliação entre a conservação da natureza e o turismo são os Parques Nacionais (PARNAs), por terem

Art. 11. [...] como objetivo básico a preservação de ecossistemas naturais de grande relevância ecológica e beleza cênica, possibilitando a realização de pesquisas científicas e o desenvolvimento de atividades de educação e interpretação ambiental, de recreação em contato com a natureza e de turismo ecológico. (Brasil, 2000)

Dentre as 334 UCs federais existentes em 2021, 137 são PARNAs, tendo sido o Parque Nacional do Caparaó (PNC) o $10^{\circ}$ a ser criado, em 1961. Os registros à época justificavam sua criação por ser "lugar excepcionalmente dotado pela natureza, ocupando posição de destaque a serra do Caparaó, ao lado do Pico da Bandeira", e que caberia então ao poder público responsabilizar-se por "resguardar as belezas naturais dessa região" (Brasil, 1961).

Nesse sentido, uma das formas de turismo que concilia o patrimônio natural e sua conservação é o de natureza, que para McKercher (2002, p. 17), "engloba o ecoturismo, turismo de aventura, turismo educacional e uma profusão de outros tipos de experiências proporcionadas pelo turismo ao ar livre e alternativo". Por sua vez, Buckley (2009) inclui nessa categoria todas as outras formas de turismo em ambientes naturais relativamente não perturbados, que são a atração ou cenário principal.

O turismo de natureza representa

as atividades realizadas em espaços naturais (protegidos ou não), motivadas pelos aspectos da natureza (seja para descansar, retornar às origens, contemplar e/ou realizar atividades que gerem adrenalina, risco ou apenas sejam realizadas em meio natural) e que certamente geram determinados impactos - ambientais e sociais - que nem sempre são percebidos ou considerados pelos turistas e pelo mercado. (Martins \& Silva, 2018, p. 501)

Embora para Wolf, Croft e Green (2019) a conservação da natureza e o turismo de natureza sejam paradoxais, os estudos relacionando lazer e meio ambiente remontam à década de 1960 (Buckley, 2009). Segundo Eagles, Haynes e McCool (2002, xv) "áreas protegidas precisam de turismo, e turismo precisa de áreas protegidas". Os segmentos turísticos desenvolvidos em áreas protegidas, como o turismo de natureza, compõem a oferta turística, que é o "conjunto de atrativos turísticos, serviços e equipamentos, e toda 
infraestrutura de apoio ao turismo de um determinado destino turístico, utilizados em atividades designadas como turísticas" (MTUR, 2007, p. 15).

Assim, pode-se considerar a região compreendida pelo Circuito Turístico (CT) "Viva Caparaó ${ }^{[1]}$ ” além de outros circuitos envoltos ao parque, como o CT "Serras, Águas e Cafezais” (ES) e o CT “Pico da Bandeira" (MG) - com uma rica oferta turística natural e cultural, a exemplo, dentre outros, do próprio PNC e seus recursos naturais protegidos, e do Caminho da Luz - via de cerca de $200 \mathrm{Km}$ entre Tombos e Alto Caparaó (MG) (Neves, 2003)-, respectivamente.

Embora para Amarante (2016) o turismo no PNC não apresente a relevância de outras atividades econômicas como a cafeicultura, a produção do café traz valor agregado qualificando suas formas de preparo e consumo, despontando como formas de Turismo Gastronômico e Agroturismo, conforme será apresentado adiante. Por sua vez, para Almeida (2015) a intensidade da visitação excede a capacidade de carga turística, em que parte da oferta turística - como estacionamentos e campings - são fatores limitantes para o desenvolvimento do turismo no PNC.

Desta forma, o presente trabalho teve como objetivo identificar a oferta do turismo de natureza no contexto do PNC, considerando a relação entre o parque, os recursos naturais, e os empreendimentos voltados ao turismo e situados no entorno espírito-santense da UC.

\section{O Parque Nacional do Caparaó}

O PNC (Figura 1), situa-se na divisa dos estados de Minas Gerais (MG) e do Espírito Santo (ES). Compreende uma área de 318 km., abrangendo nove municípios: Alto Caparaó, Alto Jequitibá, Caparaó e Espera Feliz (MG); Divino de São Lourenço, Dores do Rio Preto, Ibitirama, Irupi e Iúna (ES).

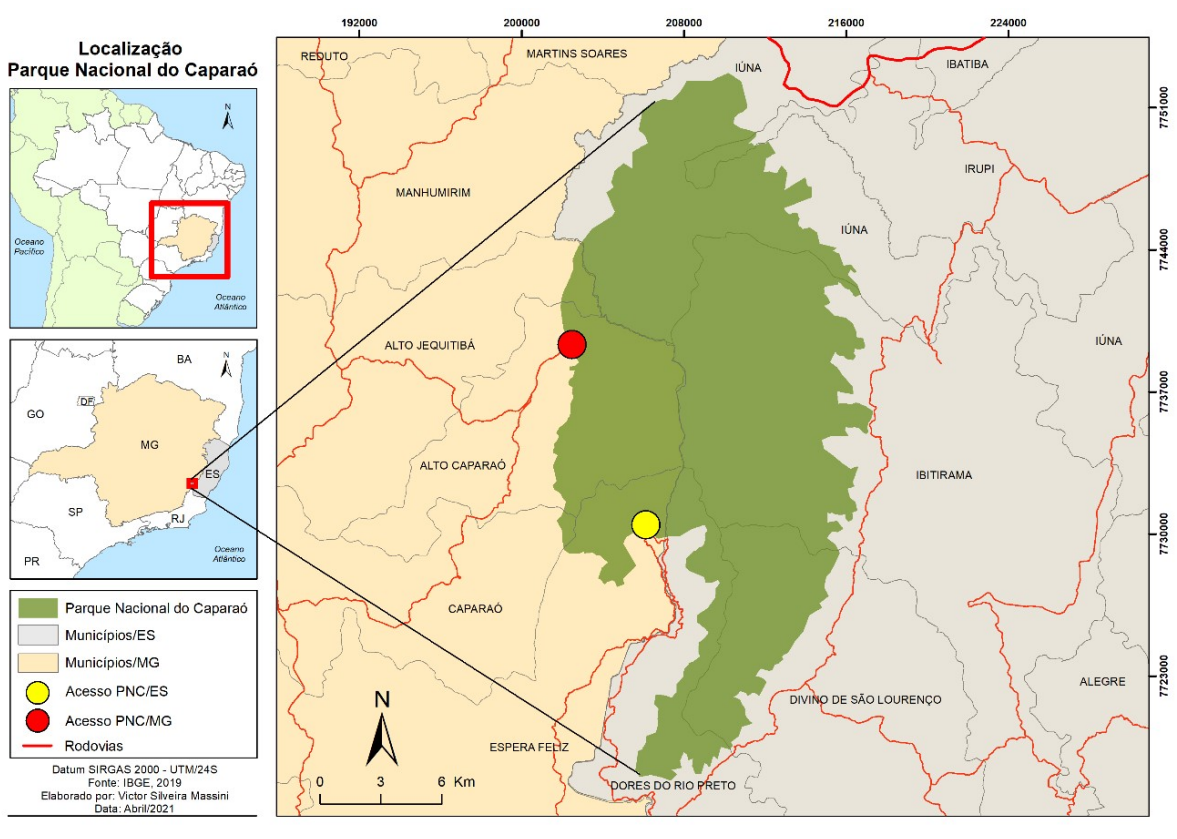

FIGURA 1

Localização e acessos do Parque Nacional do Caparaó (ES/MG).

Fonte: Dados da pesquisa, 2021

A UC é uma das áreas naturais protegidas mais conhecidas do Brasil por conter o 3. ponto mais alto do território nacional, o Pico da Bandeira (Figura 2), com $2.892 \mathrm{~m}$ de altitude, tradicionalmente buscado por turistas brasileiros e, mais recentemente, por estrangeiros. Devido às características geomorfológicas, no parque são tradicionais as atividades em montanha, sendo o uso público significantemente caracterizado 
por atividades esportivas. De maneira direta ou indireta, uma cadeia de serviços e produtos estão associados ao parque, já que são comercializados em seu entorno e de alguma maneira recorrem à temática da UC na imagem, produto ou serviço.

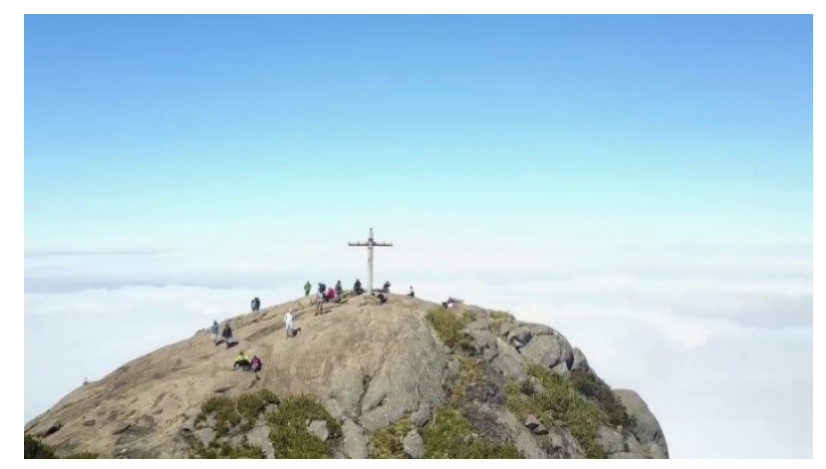

FIGURA 2

Pico da Bandeira (PNC).

Fonte: Irving Wallace, $2017^{[2]}$.

De acordo com dados divulgados pelo ICMBio, a demanda turística para o PNC apresenta constante aumento anual, de 31.472 visitantes em 2006 para 54.548 visitantes em 2015, chegando a 123.358 visitantes em 2019 (pré-pandemia do SARS-CoV-2), embora não esteja entre os mais visitados do Brasil. Em termos de contribuições econômicas, o PNC já recebeu cerca de $\mathrm{R} \$ 7.66$ milhões $\left(26^{\circ}\right.$ posição quanto às UCs federais amostradas) e empregou 243 pessoas (ICMBio, 2018a).

Sobre aspectos climáticos, na região do posto meteorológico de Alto Caparaó (MG) o registro histórico é de temperaturas entre $-4^{\circ} \mathrm{C}$ e $34^{\circ} \mathrm{C}$, sendo entre setembro e março o período com maiores temperaturas, e, entre maio e agosto, o período com menores temperaturas. Os índices de precipitação anual, que variam entre $1.000 \mathrm{~mm}$ e $1.500 \mathrm{~mm}$, contam com duas estações distintas: chuvas entre novembro e março; e estiagem entre abril e outubro (Massini \& Vale, 2018).

Para Andrade (2004) o próprio movimento turístico na região é influenciado e condicionado pelas características climáticas, a exemplo das demandas turísticas de inverno, em que turistas buscam vivenciar o frio característico das regiões de maior altitude; e nas temporadas de verão, quando buscam ter experiências propiciadas pelas temperaturas mais quentes, como a balneabilidade.

No perímetro interno do PNC as atividades são restritas e ocorrem em áreas específicas, de acordo com o zoneamento do parque, sendo que a visitação turística - e a infraestrutura voltada a esta atividade - representa o modo de uso e ocupação antrópico mais expressivo. Nas áreas externas e circundantes ao PNC o uso da terra caracteriza-se pela cultura agrária, com uma diversidade de atividades relacionadas desenvolvidas.

Como apresentado no Plano de Manejo (ICMBio, 2015), a cobertura natural da região em que o parque está inserido é marcada pela presença de fragmentos florestais intercalados com pastagens, áreas de culturas agrícolas temporárias e permanentes, corpos d'água, e áreas urbanizadas. Massini e Vale (2018), em estudo sobre as características das fitofisionomias da cobertura natural no interior da UC, identificaram diferentes classes e suas respectivas porcentagens na área total do parque, a saber: I) floresta montana (44,51\%); II) campos altimontanos (26,88\%); III) afloramento cristalino (16,33\%); IV) mata em regeneração (7,46\%); V) silvicultura (4,41\%); e outros (< que $1 \%)$.

Quanto ao potencial hidrológico, além de inúmeras nascentes, cursos d'água e piscinas naturais, que encontram-se distribuídas por todos os municípios situados na divisa territorial com a UC, circuitos de cachoeiras acessíveis ao público por trilhas têm destaque, e constituem o conjunto de atratividades turísticas no parque - "Vale Encantado" (Figura 3) e "Vale Verde", acessados pela portaria de Alto Caparaó (MG), e "Cachoeiras da Macieira", acessado pela portaria de Pedra Menina (ES). 


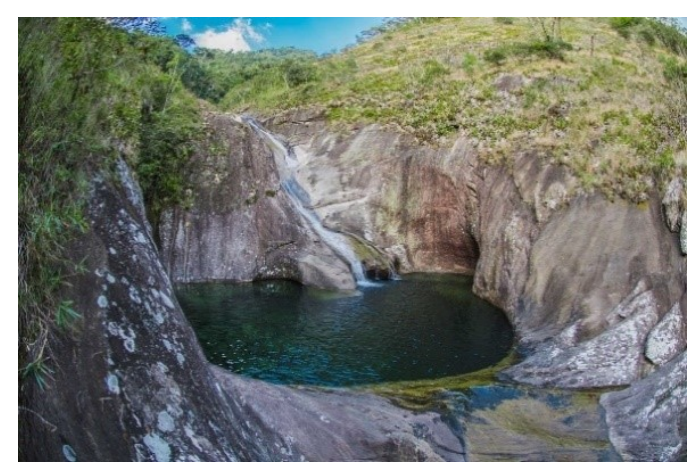

FIGURA 3

Vale Encantado (PNC).

Fonte: Viajar Melhor, $2021^{[3]}$.

Mediante a presença desses e outros recursos naturais resguardados pela UC e o aumento no índice de visitação, entre os anos de 2016 e 2018 foi realizado um "Estudo de Viabilidade Econômica e Financeira” (EVEF) pelo Ministério do Meio Ambiente (MMA) e outros órgãos ambientais, com intuito de "estabelecer bases de referência para estruturar uma política de fomento às parcerias ambientais públicoprivadas (PAPP), voltadas para a geração de oportunidades, no contexto da gestão das unidades de conservação" (ICMBio, 2016).

O governo federal busca dar continuidade às ações de concessão de UCs públicas à iniciativa privada. Assim, o PNC figura (ICMBio, 2018) ${ }^{[4]}$, entre outras UCs que compóem uma lista de prioridade para preparação e liberação de próximos editais de concessão. Por meio da Resolução Federal No 197 (ME, 2021) foi dado andamento no processo, com parecer favorável do Ministério de Economia (ME) sobre a inclusão do PNC e outras quatro UCs no Programa Nacional de Desestatização (PND) e qualificação no âmbito do Programa de Parcerias de Investimentos (PPI).

\section{Metodologia}

No primeiro momento foi realizado levantamento bibliográfico acerca do PNC (ICMBio, 2015) e do turismo de natureza (Seabra, 2001; Kinker, 2002; Morsello, 2000; Martins \& Silva, 2018). Embora para Buckley (2011) os aspectos ambientais do turismo sejam pouco estudados, para Oca Veja, SerranoBarquín, Palma-Castrejón, Cisneros e Ortega (2019) os tópicos "turismo e meio ambiente" e "impactos do turismo" estão entre os seis mais pesquisados na Ibero-américa, quando se trata da relação entre turismo e sustentabilidade ambiental.

Há que se ressaltar que as expressões, embora tragam semelhanças, não são sinônimos. A relação turismo e meio ambiente considera um escopo maior, que faz parte das relações econômicas, sociais e ecológicas do turismo (Teles, 2011). Já turismo sustentável “é a atividade que satisfaz as necessidades dos turistas e as necessidades socioeconômicas das regióes receptoras, enquanto a integridade cultural, a integridade dos ambientes naturais e a diversidade biológica são mantidas para o futuro" (OMT, 2002, p. 24).

Foram levantados e observados aspectos fisiográficos como o clima (Rizzini, 1979), a vegetação (Massini \& Vale 2018), os recursos hídricos e o uso e ocupação da terra (ICMBio, 2015). Em seguida, foram elaborados os instrumentos de coleta de dados: formulário quali-quantitativo estruturado, para inventário da oferta ecoturística, e qualitativo semiestruturado, para entrevista in loco com os atores sociais selecionados.

Para a elaboração do instrumento de coleta de dados, no formato de roteiro estruturado qualitativo, considerou-se a metodologia Survey (Babbie, 2003), contando com 34 questões, tanto de múltipla escolha 
quanto dissertativas, para ambas as amostras (gestor público e empreendedores privados), sobre temáticas ambientais, turísticas, socioeconômicas e de gestão.

Para a confecção do mapa de localização e acesso do PNC foi utilizado o software ArcGis versão 10.5, programa disponível no Laboratório de Cartografia Geográfica e Geotecnologias do Departamento de Geografia da Universidade Federal do Espírito Santo (UFES), e a base de dados do Instituto Brasileiro de Geografia e Estatística (IBGE).

Após liberação da licença de pesquisa em UC pelo Sistema de Autorização e Informação em Biodiversidade (SISBIO/ICMBio), foram realizados trabalhos de reconhecimento de campo na área limítrofe do PNC, entre junho e julho de 2016. Em um segundo momento, entre agosto e setembro do mesmo ano, realizouse a observação de campo no interior da UC, com acessos dos pesquisadores pela portaria de Pedra Menina, em Dores do Rio Preto (ES).

Entre fevereiro e abril de 2017 foram realizadas 11 entrevistas, sendo: uma com o Chefe Administrativo do PNC e dez com empreendedores turísticos locais. Os empreendimentos foram selecionados considerando o tipo de produto e/ou serviço oferecido (meios de hospedagens, centro terapêutico, equipamentos de alimentos e bebidas, condutores de atividades na natureza, espaços de eventos e espaços que dão acesso à atrativos naturais, como mirantes, cachoeiras e piscinas naturais).

Dentre os empreendimentos entrevistados, há os geridos por famílias tradicionais da região e outros que são de investidores provenientes de outras cidades e/ou estados. O tempo de atuação dos mesmos em 2017 variava entre 2 anos (o mais recente) e 15 anos (o mais antigo). Todos apresentam em comum o caráter privado e a localização geográfica, próximo à UC (entorno) e no estado do Espírito Santo.

A aplicação das entrevistas possibilitou o levantamento de informações qualitativas acerca da relação entre a atividade turística e a presença de uma UC na região, buscando compreender a dinâmica econômica e sociocultural que pode existir entre a preservação ambiental das florestas e campos altimontanos - que são ambientes naturais preservados pelo parque - e o desenvolvimento turístico local/regional, dessa forma contribuindo com o objetivo deste trabalho em identificar a oferta do turismo de natureza no contexto do PNC, considerando a relação entre a UC, os recursos naturais e os empreendimentos voltados ao turismo no entorno espírito-santense do parque.

Em seguida, na etapa final de gabinete, procedeu-se à análise dos dados a partir da compilação dos levantamentos realizados, bem como a discussão dos principais temas e conceitos com a bibliografia de referência.

\section{ANÁlise E Discussão dos RESUltados}

A atividade turística é um movimento de pessoas que se destaca como um fenômeno social, econômico e cultural. Para a Organização Mundial do Turismo (OMT, 2001, p. 38), ela "compreende as atividades que realizam as pessoas durante suas viagens e estadas a lugares diferentes a seu entorno habitual, por um período consecutivo inferior a um ano, com a finalidade de lazer, negócios ou outras".

De acordo com Lohmann e Panosso Netto (2012), mediante as diversas possibilidades de viagens (oferta turística), para as mais variadas paisagens do planeta, além de distintas motivações, por públicos que possuem modos de pensar e desejos diferentes, a prática da atividade turística foi segmentada a fim de, dentre outros fatores, manter o caráter inovador, criativo e visionário frente às tendências e mudanças sociais e econômicas globais.

Os dados gerados pela pesquisa, apresentados no Quadro 1, estão em conformidade com a ideia de que, atualmente, nota-se uma procura cada vez maior por parte dos turistas, por destinos de viagem que envolvem a estreita relação com a natureza (Buckley, 2019), e, embora a pandemia do Covid-19 tenha causado impactos negativos para comunidades receptoras - como no Parque Nacional Marinho de Fernando de Noronha (Paixão, Cordeiro \& Leite, 2020) e em PARNAs no Rio de Janeiro (Vilani, Pena \& Simões, 2021) -, as 
áreas protegidas são consideradas uma "resposta à pandemia que diminui a chance de recorrência de eventos semelhantes e permita um futuro mais sustentável para as pessoas e a natureza” (Hockings et al., 2020, p. 7).

QUADRO 1

Síntese da visão dos entrevistados sobre temas específicos

\begin{tabular}{|c|c|c|c|c|}
\hline Amostra & Conservação & Turismo & Impactos & Potencialidades \\
\hline Gestão PNC & $\begin{array}{l}\text { Compreensão } \\
\text { do PNC } \\
\text { enquanto área } \\
\text { estratégica para } \\
\text { conservação de } \\
\text { recursos } \\
\text { naturais }\end{array}$ & $\begin{array}{l}\text { O PNC enquanto } \\
\text { vetor de } \\
\text { desenvolvimento da } \\
\text { atividade turística. } \\
\text { na região; com } \\
\text { possibilidade da } \\
\text { promoção de } \\
\text { "ecoturismo } \\
\text { consciente" }\end{array}$ & $\begin{array}{l}\text { O PNC tem } \\
\text { um } \\
\text { conjunto de } \\
\text { normas que } \\
\text { balizama } \\
\text { conduta e } \\
\text { experiência } \\
\text { do visitante } \\
\text { visando } \\
\text { diminuir os } \\
\text { impactos } \\
\text { negativos } \\
\text { da visitação }\end{array}$ & $\begin{array}{l}\text { Possibilidade de } \\
\text { abertura de } \\
\text { novos atrativos } \\
\text { que } \\
\text { impulsionemo } \\
\text { desenvolvimento } \\
\text { turístico } \\
\text { regional, } \\
\text { ampliando a } \\
\text { oferta } \\
\text { qualificada para } \\
\text { outros } \\
\text { municipios }\end{array}$ \\
\hline Empresários & $\begin{array}{l}\text { A conservação e } \\
\text { a preservação } \\
\text { dos recursos } \\
\text { naturais são } \\
\text { preponderantes } \\
\text { a qualquer } \\
\text { desenvolvimento } \\
\text { turístico na } \\
\text { região, e } \\
\text { portanto a } \\
\text { natureza deve } \\
\text { ser preservada }\end{array}$ & $\begin{array}{l}\text { O turismo é e está } \\
\text { totalmente } \\
\text { relacionado ao PNC } \\
\text { e ao seu caráter } \\
\text { conservacionista As } \\
\text { atividades que } \\
\text { impulsionamo } \\
\text { turismo deveriam } \\
\text { ser fomentadas pelo } \\
\text { poder público, de } \\
\text { modo planejado e } \\
\text { participativo }\end{array}$ & $\begin{array}{l}\text { A ausência } \\
\text { de açốes do } \\
\text { poder } \\
\text { público na } \\
\text { estruturaçăo } \\
\text { do destino } \\
\text { turístico } \\
\text { (sinalização } \\
\text { e } \\
\text { informação } \\
\text { turística, } \\
\text { educação } \\
\text { ambiental), } \\
\text { associado à } \\
\text { baixa } \\
\text { qualificação } \\
\text { dos } \\
\text { serviços, } \\
\text { contribuem } \\
\text { para o } \\
\text { aumento } \\
\text { dos } \\
\text { impactos } \\
\text { negativos } \\
\text { sobre os } \\
\text { recursos } \\
\text { naturais }\end{array}$ & $\begin{array}{l}\text { Necessidade de } \\
\text { abertura de } \\
\text { novos atrativos } \\
\text { que } \\
\text { impulsionemo } \\
\text { desenvolvimento } \\
\text { turístico } \\
\text { regional; } \\
\text { necessidade de } \\
\text { apoio estatal } \\
\text { para abertura } \\
\text { de novos } \\
\text { atrativos }\end{array}$ \\
\hline
\end{tabular}

Fonte: Dados da pesquisa (2021).

Embora o Quadro 1 demonstre que entre o gestor e os empresários não há consenso quanto à gestão dos impactos causados pelo turismo de natureza, é importante ressaltar que há boas práticas quanto a padrões de regulamentação desse turismo em áreas naturais montanhosas, como nos Alpes (Siegrist \& Bonnelame, 2017), e em Parques Nacionais na Polônia (Oleśniewicz, Pytel, Markiewicz-Patkowska, Szromek \& Jandová 2020). Embora tais aspectos positivos sejam identificados em outros Parques Nacionais de altitude do Brasil, como o PARNA Itatiaia (Hübner \& Neffa, 2010) e o PARNA Monte Roraima (Silva, Cruz \& Py-Daniel, 2011), ainda se nota distanciamento entre a gestão pública e a privada no contexto do PNC.

De acordo com as "Diretrizes para uma Política Nacional de Ecoturismo": 
Ecoturismo é um segmento da atividade turística que utiliza, de forma sustentável, o patrimônio natural e cultural, incentiva sua conservação e busca a formação de uma consciência ambientalista por meio da interpretação do ambiente, promovendo o bem-estar das populações. (MMA, 2006, p. 19)

Dentro deste segmento podem ser observados diversos tipos de serviços voltados aos turistas, no intuito de suprir suas necessidades e expectativas em volta do tema principal, que é a prática de atividades relacionadas à experimentação da natureza (Dias, 2003).

Pessoas que se interessam pelo Ecoturismo buscam pelo contato com a natureza, seja no Agroturismo, no Espeleoturismo, no Turismo de Aventura (como nas práticas de montanhismo e canoagem) e alguns buscam, até mesmo, o contato mais próximo com a realidade do morador local - atraídos pela observação da autenticidade dos lugares.

Ainda de acordo com Dias (2003), esse movimento em busca de uma forma alternativa de turismo teve seu crescimento no final da década de 1980, quando houve o aumento da demanda por destinos diferenciados, ao que eram os denominados de "sol e praia", como resultado de uma mudança nos valores e hábitos que motivaram - e motivam - as pessoas na busca de melhor qualidade de vida e bem-estar, incluindo o contato mais próximo com ambientes saudáveis, por vezes cercados de natureza exuberante. Massini, Bedim e Fonseca Filho (2014), em consonância com Dias (2003), observaram que registros das primeiras incursões ecoturísticas em localidades no entorno espírito-santense do PNC foram datadas também no final da década de 1980.

Por sua vez, o envolvimento das comunidades através de um dos segmentos afins ao Ecoturismo, o Turismo de Base Comunitária (TBC), denota um turismo mais sustentável ao conciliar crescimento com desenvolvimento, conforme observado por Botelho e Rodrigues (2016), em estudos de caso de PARNAs brasileiros, em especial o da Tijuca e da Serra dos Órgãos/RJ, também com ênfase no montanhismo, e pode ser uma referência para as ações no contexto do PNC.

Quanto ao TBC, Holanda (2016) alerta para o fato de que a busca por atrativos naturais tem gerado um aumento no contingente de turistas em Parques Nacionais de todo o mundo, o que pode aumentar as divisas e ajudar na manutenção de tais áreas consideradas frágeis, embora possa também estimular a "empresarização do TBC” e destituir valores das populações tradicionais.

Ressaltando a forte relação entre os Parques Nacionais e o uso público voltado para atividades turísticas e com fins recreativos, Seabra (2001) aponta que, dentre as diversas categorias de UCs, os PARNAs apresentam maiores índices de visitação pública, o que é parcialmente motivado pelas dimensões territoriais e multiplicidade de atrativos cênicos, ecológicos e culturais.

\subsection{Olhares da gestão do PNC}

Conforme ressaltado pela gestão administrativa do PNC, menos de $2 \%$ do território brasileiro está acima da cota de 2000 metros de altitude relativa, áreas onde se pode encontrar um ecossistema de campo de altitude, com ocorrência de espécies raras e ameaçadas de extinção. Essa característica confere grande importância ao PNC, também enquanto área com potencial para pesquisas e, portanto, de produção do conhecimento científico.

Sobre a atuação do setor público, no que tange ao planejamento e organização do turismo na região do Caparaó, considera-se a existência de uma articulação entre os diferentes níveis de poder atuantes, apesar de haverem lacunas de interferência:

(...) são inexistentes as politicas que almejam fornecer recursos para viabilização de projetos que sejam de interesse comum entre os atores envolvidos e observa-se que, dentre as três esferas de poder, a municipal apresenta uma situação de maior fragilidade. (Entrevistado gestor) 
Neste aspecto, Torres e Consenza (2017) ratificam a fala do gestor, ao identificarem a falta de recursos (financeiros e humanos) como um dos principais problemas enfrentados pela gestão do PNC. Há, por parte dos governos municipais, esforços no sentido de estruturar secretarias e conselhos de turismo, porém, reconhecem que é um processo moroso e que, de fato, não apresenta resultados efetivos e valoráveis. Contudo, a instabilidade nas parcerias com o poder público local para o real desenvolvimento do parque é destacada:

(...) a dificuldade talvez seja mesmo de se criar uma agenda continuada, uma parceria mais de médio a longo prazo, com um planejamento conjunto para uma gestão também eventualmente compartilhada, pensa-se que, não do ponto de vista executivo, mas os interesses que estão relacionados ao desenvolvimento do turismo, por exemplo, se houvesse uma parceria efetiva na gestão, os recursos chegariam, e, eventualmente, o parque conseguiria compartilhar mais beneficios com as comunidades, beneficiando mais os municipios. (Entrevistado gestor)

A dificuldade apontada pelo gerente do parque à época condiz com o resultado de um estudo de Matheus e Raimundo (2017), que, ao comparar políticas de ecoturismo em áreas protegidas do Brasil e do Canadá, os autores observaram que as UCs brasileiras da categoria parque tendem a partir do princípio restritivo do uso público, o que não necessariamente leva à conservação e, possivelmente, dificulta o desenvolvimento de uma agenda de ações continuadas.

Tal agenda de planejamento a médio ou longo prazo, citada pelo gestor da UC, esbarra na relação com os stakeholders. Dados do Congresso Mundial de Parques de 2003, em publicação da IUCN (2005), já haviam apontado que os benefícios para o entorno das áreas protegidas não são equivalentes. Todavia, é necessária uma governança descentralizada, para que seja possível tanto a agenda comum, quanto o compartilhamento de benefícios (Terbogh, Schaik, Davenport \& Rao, 2002; Borrini-Feyerabend et al., 2013).

Por parte da gestão, existe um esforço em ampliar e compartilhar os benefícios (sociais, econômicos e ambientais) da existência da UC para além dos dois municípios que possuem as portarias, buscando assim, abranger diretamente as nove cidades no planejamento efetivo, já que outros municípios possuem interesse em fazer parte da UC, vislumbrando o desenvolvimento da atividade turística em seus territórios.

Contudo, a falta de demarcações que demonstrem os limites da UC é considerada um problema para a gestão do PNC, pelo favorecimento às inserções ilegais na área do parque, que ocorrem principalmente por pequenas estradas - flancos -, existentes em todo o seu entorno, no decorrer dos $150 \mathrm{~km}$ de estradas que o circundam.

Apesar de ser um conceito ainda não muito difundido entre a população local, a concepção administrativa da Zona de Amortecimento (ZAM) do PNC pretende estabelecer regras para uso, e busca apontar essas diretrizes a partir do Plano de Manejo (ICMBio, 2015) com o intuito de poder influenciar políticas públicas e planos diretores municipais das cidades do entorno, sendo notável a falta de tais políticas de desenvolvimento pensadas sob o viés da sustentabilidade, ou seja, que direcionem ações condizentes com a proposta de criação e existência da UC.

Devido a isso, é evidente a necessidade de se pensar a respeito da intensificação da ocupação urbana nas zonas rurais dos municípios limítrofes do PNC, e da escolha dos modelos econômicos de produção empregados, para que sejam condizentes com a proposta conservacionista dos recursos naturais dentro da área delimitada administrativamente para criação da ZAM do PNC.

Para promover o destino, nos últimos anos a administração da UC viu a divulgação como estratégia de desenvolvimento turístico para a região. Com isso, houve aumento na frequência de reportagens e informações acerca do PNC na mídia, o que, consequentemente, ampliou a demanda turística.

\footnotetext{
(...) o que fazemos realmente évalorizar esse espaço de mídia, que, promovendo essas inserções, o parque ganha esse alcance nacional e até internacional, a gente não perde essa oportunidade de ocupar com qualidade esses espaços e estar sempre aproveitando essa oportunidade. (Entrevistado gestor)
} 
Observa-se que, em plataformas digitais de viagens como Tripadvisor e redes sociais como Facebook, o parque apresenta alto índice de avaliação de suas infraestruturas enquanto prestador de serviços públicos para a visitação turística em ambientes naturais.

Sobre as relações entre uso público das atividades turísticas e a conservação da natureza,

(...) o parque busca seguir um conjunto de normas gerais e especificas que balizam a conduta e experiência do visitante no interior da UC, que apresenta regime especial de proteção. (Entrevistado gestor)

Tais regras visam criar condições para que as atividades aconteçam e que a UC consiga mitigar os impactos dessas visitações - que são inúmeros - tanto em relação à manutenção (limpeza, atendimento, informação, reserva), quanto em relação a pressão sobre o ambiente natural, que pode ser observada em resquícios de fogueiras, depósito irregular de lixo, pichações, depredações, etc.

A UC busca controlar o número de acessos de visitantes diariamente com base em uma capacidade de carga turística (Cifuentes, Amador, Cayot, Cruz \& Cruz, 1992), que, no caso do PNC, é de até 600 pessoas acampadas, sendo necessário agendamento prévio. Porém, para a visitação no horário de funcionamento da UC (entre $7 \mathrm{~h}$ e $18 \mathrm{~h})$, não existe um número limite de acessos.

A atividade turística é observada pela gestão da UC à época como uma ferramenta chave para a conservação dos ambientes naturais nessas áreas, sobretudo em Parques Nacionais, propiciando ao visitante que, já em sua primeira experiência in loco, possa perceber a riqueza preservada por aquela área de conservação - fauna, flora, paisagens singulares e monumentos naturais.

Junto do conjunto de regras e orientações de usos da UC, a gestão busca fazer com que o visitante perceba a si mesmo como peça fundamental na conservação e, com isso, tenha uma conduta responsável no local, desenvolvendo um processo de sensibilização e educação ambiental (EA), oferecendo informações relacionadas à necessidade e importância de preservação dos recursos e ambientes naturais ali resguardados.

Para a gestão administrava, desde a criação do PNC, "ele se tornou cada vez mais fundamental para o desenvolvimento regional com base no turismo". No contexto atual, vislumbra-se um grande potencial de desenvolvimento turístico na região - apesar de já ser histórico -, a partir da possibilidade de abertura de novos atrativos em todo o entorno, que, se operados de maneira ordenada, podem gerar um crescimento constante nos índices de visitação do PNC, influenciando toda a cadeia econômica, gerando demanda por empreendimentos que ofertem serviços associados às atividades turísticas.

Como consequência do desenvolvimento econômico na região, observou-se que é significativo o aumento constante no valor dos terrenos em todo o entorno do PNC, sendo cada vez mais difícil encontrar áreas disponíveis, conforme o que é apresentado por Ulph e Reynolds (1981), e por Beni (2001), como "efeito inflacionário" do turismo.

Dentre os empreendimentos que figuram no contexto turístico encontram-se restaurantes; hospedagens; espaços de entretenimento, lazer e descanso; cooperativas de artesanato e associações comunitárias locais; transportadoras turísticas; pontos de informações turísticas; atividades agroindustriais (e.g. café, doces, leite, queijo e pão) e condutores ambientais.

De acordo com a gestão do PNC, busca-se a constituição de um destino turístico cujos empreendimentos que o integram sejam condizentes com a ideia de conservação da UC, criando elos de conexões estreitos. Ou seja, que os empreendimentos reconheçam e respeitem as limitações inerentes quanto à localização dos mesmos na ZAM do parque.

Contudo, a oferta de capacitações/qualificações para contribuir com o empreendedorismo turístico das comunidades locais e com aspectos relacionados à qualidade na prestação de serviços.

Assim, as atividades turísticas são desenvolvidas além do que a própria UC oferece, ou seja, no conjunto de outros atrativos distribuídos no parque e entorno, inclusive interagindo com aspectos agroturísticos de base comunitária, relevantes para a cultura agrícola do café especial da serra do Caparaó, que tem se tornado conhecido internacionalmente entre apreciadores por sua qualidade premiada. 
O produto café tornou-se um componente importante da cultura local, e está associado a cadeia turística da região, oferecendo aos visitantes experiências que vão desde o processo de plantio - visitando lavouras - à colheita, conhecendo a preparação final e degustando esse símbolo regional. Grande parte desses empreendimentos constituem-se sobre a principal atividade econômica familiar, que é a agricultura cafeeira, e portanto configuram a prática do Agroturismo.

De modo geral, a carência de políticas públicas voltadas ao turismo são um dos principais entraves para o desenvolvimento regional, de acordo com a gestão do PNC. A exemplo disso, assinala-se o projeto da "estradaparque" (Soriano, 2006) da região, que visa ser justamente um elo entre turismo e economia local, por ser onde estão distribuídos grande parte dos empreendimentos turísticos e também das comunidades. Porém, a estrada não foi totalmente finalizada e, em algumas partes, a situação já não é adequada, devido à falta de manutenção, além da ausência generalizada de sinalização - placas informativas, e demais formas de comunicação com os visitantes.

O mercado do turismo executa o papel de comercializar os espaços, que no caso do Ecoturismo muitas vezes é a natureza intacta. Por não haver a devida preocupação com o futuro (longo prazo) dos recursos, e sim com lucro imediato, destinos são demasiadamente explorados e impactados negativamente, degradados de forma significativa, sofrendo com as visitações em massa. Tais aspectos condizem com as observações levantadas pela gestão administrativa do parque e demais empreendedores da região, que reconhecem o risco do uso exploratório e sem controle dos ambientes naturais da UC e de seu entorno.

Ainda por parte da gestão do PNC, visualiza-se a possibilidade de ser o Ecoturismo uma ferramenta de planejamento, desenvolvimento e estruturação de áreas mantenedoras de patrimônios, sejam naturais, culturais ou outros, porém, reconhece-se a indispensabilidade de políticas públicas, planejamentos e ações em conformidade com a realidade, conscientes e eficazes.

Para Dias (2003) os impactos das atividades turísticas sobre o meio ambiente é algo inevitável. A proposta de um turismo sustentável (OMT, 2002) é a de controlar e evitar as modificações ambientais que possam se tornar irreversíveis, não prejudicando assim a disponibilidade e qualidade dos recursos naturais que atendem as necessidades da sociedade em geral.

Complementarmente, Vanço (2018) apresenta o olhar dos moradores e visitantes quanto à percepção ambiental e econômica do caráter conservacionista do PNC que, mesmo diante das proibições impostas pelo Plano de Manejo - que são geradoras de conflitos (Souza \& Milanez, 2019) -, gera emprego e renda para os moradores por meio do turismo, sendo visto como uma oportunidade econômica diante das restriçóes.

\subsection{Olhares dos empreendedores de Turismo da área espírito-santense do PNC}

Os proprietários dos empreendimentos turísticos entrevistados relataram que o público visitante é significativamente marcado pela presença familiar, apresentando as mais diversas configurações e idades. Alguns empreendimentos relataram receber e oferecer atendimento à um público cuja renda é mais elevada, proveniente de cidades próximas à região do Caparaó, principalmente dos estados do Espírito Santo, Minas Gerais e Rio de Janeiro.

A sazonalidade turística, "um desequilíbrio temporal no fenômeno do turismo, (...) como número de visitantes (...) em atrações” (Butler, 1994, p. 332), é relatada pelos empreendedores e pode ser explicada em decorrência do tipo de serviço oferecido por cada empreendimento, podendo ter maior índice de procura em determinado período climático do ano. Os feriados e as férias escolares de janeiro e julho também foram destacados como períodos que possuem expressivo fluxo de visitantes na região do PNC.

(...) o conceito de alta temporada tem mudado, já se percebe que a visitação de novembro a março também já é expressiva, inclusive ano passado (2016) e esse ano (2017) também se reproduziu, em janeiro fomos tão procurados quanto em julho, que é um mês que geralmente é o pico da visitação. (Entrevistado Empresário 1) 
Em relação aos atrativos turísticos da região do $\mathrm{PNC}$, destacam-se como mais procurados o próprio parque e sua beleza cênica, com vegetação de Mata Atlântica em grande parte preservada, campos altimontanos (Rizzini, 1979), inúmeras corredeiras d'água, e picos - principalmente o da Bandeira. Aspectos como as águas límpidas, baixas temperaturas e rica biodiversidade, que estão relacionados a fatores ambientais (geomorfológicos, climáticos e hidrológicos) da região, também foram citados nas entrevistas. Tais fatores propiciam a prática de atividades relacionadas à ecologia, através da contemplação da beleza natural, superação de desafios, e experimentação da cultura local.

(...) a contemplação da paisagem, a conquista de se chegar ao cume do Bandeira, as cachoeiras da região, que são piscinas naturais belissimas em ambiente de mata atlântica muito preservada, verdadeiros cartóes postais que divulgam muito essa parte do turismo. (Entrevistado Empresário 1)

O parque tem uma tradição de visitação no inverno, o que é associado ao componente do frio, por conta de ser um dos poucos lugares no Brasil que a temperatura cai significantemente abaixo de zero graus célsius, e isso é bastante curioso do ponto de vista do turismo aqui para a região e atrai gente não só para visitação no parque, mas também aqui no entorno dele, que a gente chama de alta temporada de visitação que geralmente vai de maio a setembro, na invernada. (Entrevistado Empresário 7)

Sobre os atrativos culturais da região, tiveram destaque manifestações do distrito de Patrimônio da Penha, localizado no município de Divino de São Lourenço (ES), porém não isoladamente. O mesmo distrito integra, há alguns anos, uma rota nacional e internacional de turismo alternativo, com eventos que envolvem terapias holísticas alternativas, abrangendo misticismo e religiosidade (Massini et al., 2014).

Foram citados ainda: a gastronomia típica da região, eventos como passeios de bicicleta e as cavalgadas, o folclore de algumas localidades, e os próprios empreendimentos instalados entorno do parque, que têm buscado se qualificar cada vez mais e desenvolver a integração entre recursos humanos e naturais; bem como a cultura agrícola da produção cafeeira, que aponta nos últimos anos como um produto de destaque na cadeia agroturística local/regional.

Todos os entrevistados afirmaram que a preservação e a conservação dos ambientes naturais, como as florestas e os campos altimontanos (Rizzini, 1979) encontrados no PNC, são favoráveis ao desenvolvimento turístico na região. As justificativas baseiam-se no fato de que a preservação e conservação são consideradas fundamentais na garantia de recursos de diversas ordens para todas as comunidades que se encontram em volta do parque e para além delas (e.g. recursos hídricos), e que, portanto, devem ser uma preocupação preponderante a qualquer desenvolvimento na região, inclusive o do setor turístico, que se beneficia dos ambientes e recursos assegurados pelas regras de proteção.

(...) nós somos totalmente envoltos ao parque, então a sua conservação e a sua preservação são preponderantes a qualquer desenvolvimento turistico aqui, ao que tem e ao que virá, então para mim, é fundamental essa preservação. (Entrevistado Empresário 8)

Vislumbra-se o turismo como um campo de oportunidades para o surgimento e consolidação de novos negócios e empreendimentos na região, desde que busquem estar associados à ideia conservacionista proposta pela UC. A sinergia economia-ecologia presente na fala dos empresários (1 e 8) é referendada por Souza, Thapa, Rodrigues e Imori (2019).

(...) isso é bastante claro quando a gente observa a economia local, a quantidade de empreendimentos turisticos que existem, pousadas e outros, enfim, é uma cadeia que ainda está em desenvolvimento, mas pode se afirmar que o que tem hoje cresceu basicamente em torno da influência do parque, mas agora, recentemente, a gente percebe que outros atrativos do entorno também estão em sinergia com os atrativos do parque, e tem potencializado o desenvolvimento do turismo. (Entrevistado Empresário 1)

Para os empreendedores entrevistados, a principal dificuldade de desenvolvimento turístico na região assim como para a gestão administrativa do PNC - é creditada à falta de planejamento e políticas públicas, tanto aquelas que visem o estabelecimento de uma infraestrutura básica adequada (coleta de lixo, saneamento básico etc.), quanto às mais específicas, que dariam condições de crescimento e direcionariam a evolução do 
setor turístico na região. O que corrobora a análise de Scalco e Souza (2018) ao apontarem a escassez de infraestrutura como um dos gargalos na gestão da Área de Proteção Ambiental Estadual das Águas Vertentes (MG).

Reconhece-se entre os empreendedores que, para o desenvolvimento do setor turístico local/regional, há dependência, em grande parte das situações, de atitudes e iniciativas dos próprios investidores, como, por exemplo, o fato de recair sobre estes a obrigação de executar ações que promovam e facilitem a vinda dos visitantes até os estabelecimentos, através de melhorias de sinalização, informação, provimento de acesso, qualificação dos recursos humanos locais, entre outras demandas.

Contanto, há consenso na visão da gestão do parque e dos empreendedores, e que coincide com a de Calatrava (1993), que destaca a atividade turística como importante vetor de desenvolvimento, pois interage com diversos setores da economia, induzindo ao crescimento.

O desenvolvimento do setor econômico através de atividades turísticas - à medida que se torna mais realçado na realidade das comunidades como possibilidade de entrada de renda - caminha atrelado à necessidade de desenvolvimento do sentimento comunitário de pertencimento e de conscientização em relação à preservação e conservação dos ambientes naturais, que configuram o cerne da oferta turística na região da serra do PNC.

\section{Considerações Finais}

Após o aprofundamento sobre questões de organização e em que se baseiam as atividades turísticas desenvolvidas na área envolta ao contexto do PNC, observa-se que essa atividade (em especial o turismo de natureza), tem relevância para as comunidades da região, sobretudo dos municípios circundantes ao parque.

Neste cenário, o PNC, assim como outras UCs federais do Brasil, é destacado pelo órgão gestor como uma área onde encontra-se um panorama de intensa e contínua expansão, representada na ocupação e urbanização das áreas do entorno, com o aumento progressivo da busca por terras e execução de investimentos, consequentemente desenvolvendo um cenário de especulação imobiliária na região, também denominado de efeito inflacionário.

O aumento da procura por áreas naturais - em especial nas previsões pós-pandemia do novo coronavírus - vem transformando as atividades econômicas tradicionais das comunidades do entorno do parque em atividades características do setor do turismo (e.g. meios de hospedagem, equipamentos de alimentação, agências de turismo, transportadoras turísticas e guias de turismo).

O potencial da UC para o turismo de natureza e segmentos afins, como Ecoturismo, Geoturismo, Turismo Rural e TBC, é induzido pelos empresários locais, e também fomentado por seu próprio fluxo ou demanda turística. Justifica-se, assim, a presente pesquisa, já que a maioria dos estudos no PNC até o momento foram voltados ao conhecimento da biodiversidade e impactos socioambientais.

Como limitações desse estudo, considera-se o distanciamento temporal das entrevistas, realizadas em 2017 , assim como a mudança de gestão e, possivelmente, de algum empresário entrevistado. Todavia, a rotatividade de gestores de UCs, somada ao curto ciclo de vida de micro e pequenas empresas no Brasil, atestam que a amostragem teve sua validade por apontar um momento recente específico dessa unidade, estimulando a continuidade de pesquisas.

Desta maneira, o conteúdo das entrevistas realizadas é um valioso registro para identificação da estreita relação entre o desenvolvimento do turismo de natureza e a conservação de áreas naturais protegidas. Esta mesma relação aponta que, caso o desenvolvimento regional não seja pautado em um planejamento participativo (que considere os diversos atores envolvidos no processo) e com foco na sustentabilidade (caso esta não seja uma prioridade e um objetivo em comum), ocorrerá uma maior degradação do patrimônio resguardado pela UC e seu entorno imediato, seja natural ou cultural, comprometendo a qualidade de vida da biodiversidade, das comunidades, e do turismo. 


\section{REFERÊNCIAS}

Almeida, M. P. de (2015). Avaliação do manejo da visitação no Parque Nacional do Caparaó - MG. [Dissertação de Mestrado, DEF/UFV]. Viçosa (MG). Recuperado de https://www.locus.ufv.br/bitstream/123456789/7366/ 1/texto\%20completo.pdf.

Amarante, F. B. (2016). A influência da criação do Parque Nacional do Caparaó (1961-2014) sobre a mudança da paisagem em Alto Caparaó-MG: sob a perspectiva do turismo. [Dissertação de Mestrado, DEHIS/UFV]. Viçosa (MG). Recuperado de https://www.locus.ufv.br/bitstream/123456789/10054/1/texto\%20completo.pdf.

Andrade, J. V. (2004). Turismo: fundamentos e dimensões. Editora Ática.

Babbie, E. (2003). Métodos de pesquisa survey. Editora da UFMG.

Beni, M. C. (2001). Análise estrutural do turismo. SENAC São Paulo.

Borrini-Feyerabend, G., Dudley, N., Jaeger, T., Lassen, B. B., Neema, P., Phillips, A., \& Sandwith, T. (2013). Governance of Protected Areas. From understanding to action. Gland, IUCN. Recuperado de https://www.iucn. org/sites/dev/files/content/documents/governance_of_protected_areas_from_understanding_to_action.pdf.

Botelho, E. S., \& Rodrigues, C. G. O. (2016). Inserção das iniciativas de base comunitária no desenvolvimento do turismo em parques nacionais. Caderno Virtual de Turismo, 16(2), 280-295.

Brasil. (1961). Decreto no 50.646. Cria o Parque Nacional de Caparaó e dá outras providências. Brasília: Governo Federal.

Brasil. (2000). Lei no 9.985. Regulamenta o art. 225, $§ 1^{\circ}$, incisos I, II, III e VII da Constituição Federal, institui o Sistema Nacional de Unidades de Conservação da Natureza e dá outras providências. Brasília: Governo Federal.

Buckley, R. C. (2009). Ecotourism: Principles and Practices. CAB International.

Buckley, R. C. (2011). Tourism and environment. Annual Review of Environment and Resources, 36, 397-416.

Buckley, R. C. (2019). Nature tourism and mental health: parks, happiness, and causation. Journal of Sustainable Tourism, 28(9), 1-16.

Butler, R. Seasonality in Tourism: issues and problems. In: Seaton, A. et al. (eds.) (1994). Tourism - The State of the art. Wiley, p. 332-339.

Calatrava, J. (1993). El turismo rural como recurso endógeno en el desarrollo local: Consideraciones teóricas y comentarios sobre las Alpujarras Altas Occidentales. Universidad de Córdoba.

Cifuentes, M., Amador, E., Cayot, L., Cruz, E., \& Cruz, F. (1992). Determinación de capacidad de carga turística em áreas protegidas. CATIE.

Dias, R. (2003). Turismo Sustentável e Meio Ambiente. Atlas.

Eagles, P. J., Haynes, C., \& McCool, S.F. (2002). Sustainable tourism in protected areas. Guidelines for planning and management. Cambridge: International Union for Conservation of Nature and Natural Resources / The United Nations Environment Program and the World Tourism Organization.

Hockings, M. et al. (2020). COVID-19 and protected and conserved areas. Parks Journal, 26(1), 7-24.

Holanda, L. A. (2016). Empresarização do turismo de base comunitária. Caderno Virtual de Turismo, 16(2), 249-262.

Hübner, D. G., \& Neffa, E. M. (2010). Parque Nacional do Itatiaia: uma análise contextual. Revista REUNA, 15(2), 41-58.

ICMBio. (2015). Plano de Manejo do Parque Nacional do Caparaó. Brasília, Instituto Chico Mendes de Conservação da Biodiversidade.

ICMBio. (2016). Estudo de Viabilidade Econômica Financeira. Brasília: Instituto Chico Mendes de Conservação da Biodiversidade.

ICMBio. (2018a). Contribuiçôes do turismo em unidades de conservação para a economia brasileira. Brasília: Instituto Chico Mendes de Conservação da Biodiversidade. 
ICMBio. (2018b). Parques do Brasil: visitar é proteger! Estratégias de implementação da visitação em unidades de conservação federais: prioridades de execução 2018-2020. Brasília: Instituto Chico Mendes de Conservação da Biodiversidade.

IUCN. (2005). Benefits Beyond Boundaries. Report of the Vth IUCN World Parks Congress. Gland, IUCN. Recuperado de https://portals.iucn.org/library/sites/library/files/documents/2005-007.pdf.

Kinker, S. (2002). Ecoturismo e conservação da natureza em parques nacionais. Papirus.

Lohmann, G., \& Panosso Netto, A. (2012). Teoria do Turismo: conceitos, modelos e sistemas. $2^{\text {a }}$ ed. Aleph.

Martins, P. C. S., \& Silva, C. A. (2018). Turismo de Natureza ou na Natureza ou Ecoturismo? Reflexões e contribuições sobre um tema em constante debate. Revista Turismo em Análise, 29(3), 487-505.

Massini, V. S., Bedim, B. P., \& Fonseca Filho, R. E. (2014). O turismo em Patrimônio da Penha (ES) e suas interfaces com o Parque Nacional do Caparaó. Revista Brasileira de Ecoturismo, 7(4), 715-734.

Massini, V. S., \& Vale, C. C. (2018). A cobertura natural, o potencial paisagístico e o turismo no Parque Nacional do Caparaó (ES/MG). Revista Caminhos de Geografia, 19(67), 253-267.

Matheus, F. S., \& Raimundo, S. (2017). The results of Ecotourism policies in protected areas in Brazil and Canadá. Revista Brasileira de Pesquisa em Turismo, 11(3), 454-479.

McKercher, B. (2002). Turismo de Natureza: planejamento e sustentabilidade. Contexto.

ME. (2021). Resolução $n^{\circ}$ 197. Opina pela qualificação no âmbito do Programa de Parcerias de Investimentos e pela inclusão no Programa Nacional de Desestatização, para fins de concessão para prestação de serviços públicos de apoio à visitação, com previsão de custeio de ações de apoio à conservação, à proteção e à gestão das referidas unidades de conservação. Brasília: Ministério da Economia. Recuperado de: https://www.in.gov.br/em/web/d ou/-/resolucao-n-197-de-25-de-agosto-de-2021-344471737.

Morsello, C. (2000). Programa de uso público do Parque Nacional do Caparaó. Brasília: Ibama.

MMA. (2004). Gestão participativa do SNUC. Brasília: Ministério do Meio Ambiente.

MMA. (2006). Diretrizes para Visitação em Unidades de Conservação. Brasília: Ministério do Meio Ambiente, dos Recursos Hídricos e da Amazônia Legal/Ministério da Indústria, do Comércio e do Turismo.

MTUR. (2007). Programa de Regionalização do Turismo - Roteiros do Brasil: Módulo Operacional 8 - Promoção e Apoio à Comercialização. Brasília: Ministério do Turismo.

Oca Vega, P. I. M., Serrano-Barquín, R. C., Palma-Castrejón, D., Cisneros, H. F., \& Ortega, O. A. S. (2019). Sustentabilidad y Turismo. Una Aproximación a la producción en Iberoamérica. CULTUR, 13(1), 114-135.

Oleśniewicz, P., Pytel, S., Markiewicz-Patkowska, J, Szromek, A.R., \& Jandová, N. (2020). A Model of the Sustainable Management of the Natural Environment in National Parks - A Case Study of National Parks in Poland. Sustainability, 12(2704), 1-28.

Paixão, W. B., Cordeiro, I. J. D., \& Leite, N. K. (2021). Efeitos da pandemia do COVID-19 sobre o turismo em Fernando de Noronha ao longo do primeiro semestre de 2020. Revista Brasileira de Pesquisa em Turismo, 15(1), $1-20$.

Rizzini, C. T. (1979) Tratado de fitogeografia do Brasil: aspectos ecológicos, sociológicos e florísticos. Âmbito Cultural Edições.

Scalco, R. F., \& Souza, D. E. (2018). Área de Proteção Ambiental Estadual das Águas Vertentes: instrumentos de gestão e potencial turístico. Caderno Virtual de Turismo, 18(3), 22-43.

Seabra, G. F. (2001). Ecos do Turismo: o turismo ecológico em áreas protegidas. Papirus.

Siegrist, D., \& Bonnelame, L. K. (2017). Nature-based tourism and nature protection: quality standards for travelling in protected areas in the Alps. Eco.mont, 9(special issue), 29-34.

Silva, R.D.M., Cruz, J., \& Py-Daniel, V. (2011). Monte Roraima na América do Sul, Venezuela: Destino Mundial do Turismo de Natureza. PASOS. Revista de Turismo y Patrimonio Cultural, 9(2), 411-422.

Soriano, A. J. S. (2006). Estrada-parque: uma proposta para definição. UNESP.

Souza, L. R. C., \& Milanez, B. (2019). Comunidades e unidades de conservação: conflitos socioambientais de segunda ordem no entorno do Parque Nacional do Caparaó. Caminhos de Geografia, 20(69), 403-420. 
Souza, T. V. S. B., Thapa, B., Rodrigues, C. G. O., \& Imori, D. (2019). Economic impacts of tourism in protected areas of Brazil. Journal of Sustainable Tourism, 27(6), 735-749.

Takahashi, L. Y. (2004). Uso público em Unidades de Conservação. Fundação O Boticário de Proteção da Natureza.

Terbogh, J., Schaik, C.v., Davenport, L., \& Rao, M. (Org.) (2002). Tornando os parques eficientes. Estratégias para a Conservação da natureza nos trópicos. Ed. UFPR.

Torres, R., \& Consenza, B. (2017). Avaliação da gestão e sustentabilidade do Parque Nacional do Caparaó (Estados de Minas Gerais e Espírito Santo), Brasil. Revista Brasileira de Gestão Ambiental Sustentável, 4(8), 395-419.

Ulph, A. M., \& Reynolds, I. K. (1980). An economic evaluation of National Parks. Centre for Resource and Environmental Studies, Australian National University.

Vanço, V. (2018). Percep̧ça Ambiental dos moradores e turistas em relação ao Parque Nacional do Caparaó. (Trabalho de Conclusão de Curso em Geografia) - UFU, Uberlândia (MG).

Oca Vega, P. I. M., Serrano-Barquín, R. C., Palma-Castrejón, D., Cisneros, E. F., \& Ortegas, O. A. S. (2019). Sustentabilidad y Turismo. Una aproximación a la producción en Iberoamérica. CULTUR, 13(1), 114-135.

OMT. (2002). Contribuciones de la organización mundial del turismo a la cumbre mundial sobre el desarrollo sostenible. Johannesburgo: Organización Mundial del Turismo.

Teles, R. M. de S. (2011). Turismo e meio ambiente ou turismo de natureza? Alguns apontamentos para organização dessa modalidade. In. R. M. de S. Teles (Org.). Turismo e meio ambiente. (pp. 3-20). Elsevier.

Vilani, R. M., Pena. R. C., \& Simões, B. F. T. (2020). Ecoturismo no Pós-COVID-19 no Parque Nacional da Tijuca e Parque Estadual da Pedra Branca. Revista Brasileira de Ecoturismo, 13(4), 671-688.

Wolf, I. D., Croft, D. B., \& Green, R. J. (2019). Nature Conservation and Nature-Based Tourism: A Paradox? Environments, 6(104), 1-22.

\section{Notas}

[1] Nominado Circuito Turístico "Caparaó Capixaba” entre 2010 e 2021.

[2] Recuperado de https://www.youtube.com/watch?v=fUtJ4KvX7tw.

[3] Recuperado de https://guiaviajarmelhor.com.br/cachoeira-nas-alturas-conheca-o-vale-encantado-no-parque-nacionaldo-caparao/.

[4] Recuperado de https://www.icmbio.gov.br/portal/ultimas-noticias/20-geral/9822-aberta-consulta-publica-parasubsidiar-editais-de-concessoes. 